\title{
Effects of atomoxetine on growth in children with attention- deficit/hyperactivity disorder following up to five years of treatment.
}

\author{
Thomas J. Spencer \\ Harvard University \\ Christopher J. Kratochvil \\ University of Nebraska Medical Center, ckratoch@unmc.edu \\ R. Bart Sangal \\ Attention Disorders Institute \\ Keith E. Saylor \\ Neuroscience, Inc. \\ Charles E. Bailey \\ Psychiatric Institute of Florida \\ Tell us how you used this information in this short survey. \\ Follow this and additional works at: https://digitalcommons.unmc.edu/com_psych_articles \\ See next page for additional authors \\ Part of the Psychiatry Commons
}

\section{Recommended Citation}

Spencer, Thomas J.; Kratochvil, Christopher J.; Sangal, R. Bart; Saylor, Keith E.; Bailey, Charles E.; Dunn, David W.; Geller, Daniel A.; Casat, Charles D.; Lipetz, Robert S.; Jain, Rakesh; Newcorn, Jeffrey H.; Ruff, Dustin D.; Feldman, Peter D.; Furr, Amanda J.; and Allen, Albert J., "Effects of atomoxetine on growth in children with attention-deficit/hyperactivity disorder following up to five years of treatment." (2007). Journal Articles: Psychiatry. 12.

https://digitalcommons.unmc.edu/com_psych_articles/12

This Article is brought to you for free and open access by the Psychiatry at DigitalCommons@UNMC. It has been accepted for inclusion in Journal Articles: Psychiatry by an authorized administrator of DigitalCommons@UNMC. For more information, please contact digitalcommons@unmc.edu. 


\section{Authors}

Thomas J. Spencer, Christopher J. Kratochvil, R. Bart Sangal, Keith E. Saylor, Charles E. Bailey, David W. Dunn, Daniel A. Geller, Charles D. Casat, Robert S. Lipetz, Rakesh Jain, Jeffrey H. Newcorn, Dustin D. Ruff, Peter D. Feldman, Amanda J. Furr, and Albert J. Allen 


\title{
Effects of Atomoxetine on Growth in Children with Attention-Deficit/Hyperactivity Disorder Following up to Five Years of Treatment
}

\author{
Thomas J. Spencer, M.D., ${ }^{1}$ Christopher J. Kratochvil, M.D., ${ }^{2}$ R. Bart Sangal, M.D., ${ }^{3}$ \\ Keith E. Saylor, Ph.D., ${ }^{4}$ Charles E. Bailey, M.D. ${ }^{5}$ David W. Dunn, M.D., ${ }^{6}$ \\ Daniel A. Geller, M.B.B.S., ${ }^{1}$ Charles D. Casat, M.D., ${ }^{7}$ Robert S. Lipetz, D.O., ${ }^{8}$ \\ Rakesh Jain, M.D., ${ }^{9}$ Jeffrey H. Newcorn, M.D., ${ }^{10}$ Dustin D. Ruff, Ph.D., ${ }^{11}$ \\ Peter D. Feldman, Ph.D., ${ }^{11}$ Amanda J. Furr, B.Sc., ${ }^{6}$ and Albert J. Allen, M.D., Ph.D. ${ }^{11}$
}

\begin{abstract}
Objective: To examine the effects on growth of long-term pharmacological treatment for attention-deficit/hyperactivity disorder (ADHD), we present findings from an ongoing 5-year study of the efficacy and safety of treatment with atomoxetine.

Methods: North American patients, $6-17$ years old at study entry $(N=1,312)$ and with $D i$ agnostic and Statistical Manual of Mental Disorders, 4th edition (DSM-IV) ADHD, were studied under open-label atomoxetine treatment. Sixty-one were studied up to 5 years.

Results: After 1 month's treatment, patients weighed less than expected from their starting percentiles relative to population norms, with a maximum shortfall at 15 months and a return to expected weight by 36 months. Patients were slightly shorter than expected after 12 months, reaching a maximum shortfall at 18 months and returning to expected height by 24 months. Patients in the top quartile for body mass index (BMI) or weight at baseline, and those in the third quartile for height, showed 5-year decreases from expected values. Those below median height at baseline showed increases relative to expected values.

Conclusions: These interim results indicate that continuous atomoxetine treatment for up to 5 years has little or no long-term effect on juvenile growth and final stature for most patients, although persistent decreases from expected may occur in some patients who are larger than average before treatment.
\end{abstract}

\footnotetext{
${ }^{1}$ Massachusetts General Hospital / Harvard Medical School, Boston, Massachusetts.

${ }^{2}$ University of Nebraska Medical Center, Omaha, Nebraska.

${ }^{3}$ Attention Disorders Institute, Troy, Michigan.

${ }^{4}$ Neuroscience, Inc., Herndon, Virginia.

${ }^{5}$ Psychiatric Institute of Florida / Clinical Neuroscience Solutions, Orlando, Florida.

${ }^{6}$ Indiana University School of Medicine, Indianapolis, Indiana.

${ }^{7}$ Behavioral Health Center, Carolinas HealthCare System, Charlotte, North Carolina.

${ }^{8}$ Encompass Clinical Research, Spring Valley, California.

${ }^{9} \mathrm{R} / \mathrm{D}$ Clinical Research, Inc., Lake Jackson, Texas.

${ }^{10}$ Mount Sinai Medical Center, New York, New York.

${ }^{11}$ Lilly Research Laboratories, Eli Lilly and Company, Indianapolis, Indiana.

Statistical consultant: Dustin D. Ruff, Ph.D.

This work was sponsored by Eli Lilly and Company.
} 


\section{INTRODUCTION}

A TTENTION-DEFICIT / HYPERACTIVITY DISORDER (ADHD) is one of the most common psychiatric disorders in childhood, with an incidence rate estimated at between $3 \%$ and $7 \%$ (American Psychiatric Association 2000) in the United States and similar rates found in other regions of the world (Wang et al. 1993; Andres Carrasco et al. 1995). In many patients, the disorder persists through adolescence and into adulthood, requiring chronic treatment over many years. Pharmacotherapy for ADHD has relied for several decades on the psychostimulants, particularly dextroamphetamine and methylphenidate $(\mathrm{MPH})$, but the range of choices of medication has been considerably expanded with the introduction of a nonstimulant treatment, atomoxetine.

Studies conducted with both the psychostimulants and atomoxetine indicate that, at least acutely, treatments for ADHD among children and adolescents are associated with significant suppression of growth in height and weight (Safer et al. 1972; Michelson et al. 2001; Sund and Zeiner 2002; MTA Cooperative Group 2004; Spencer et al. 2005). However, few studies have been carried out past the 2-year time point, and the long-term effects on growth of treatment for ADHD are still unclear. To address this gap, we sought to examine the effects of continuous atomoxetine treatment on height and weight among children and adolescents with ADHD over a span of up to 5 years, testing the hypothesis that suppression of growth in height and weight is a temporary phenomenon. The 2-year interim results have been published previously (Spencer et al. 2005).

\section{METHODS}

\section{Patient sample and study design}

Recently, we analyzed the first set of 5-year data from an ongoing 5-year longitudinal study of the efficacy, safety, and tolerability of longterm treatment with atomoxetine. The data set includes all patients from previous Lilly clinical trials of atomoxetine (13 studies: 6 placebocontrolled, 7 open-label) who entered open-label atomoxetine treatment. This report presents the data on patients' weight, height, and body mass index (BMI). Patients were children and adolescents 6-17 years of age at the time of initial study enrollment, either male or female, weighing at least $20 \mathrm{~kg}$ at baseline, and had been diagnosed with ADHD, as defined in the Diagnostic and Statistical Manual of Mental Disorders, 4th edition (DSM-IV) (American Psychiatric Association 1994), and confirmed with the Schedule for Affective Disorders and Schizophrenia for School-age Children, Present and Lifetime Version (K-SADS-PL; Kaufman et al. 1996). The drug development program allowed patients who entered and completed a shortterm study the option of continuing treatment in an extension study for a total exposure of up to 5 years. Pre-extension trials ranged from 6 to 96 weeks in duration and used similar dose ranges, with a starting dose of $0.5 \mathrm{mg} / \mathrm{kg}$ per day, a target dose of $1.2 \mathrm{mg} / \mathrm{kg}$ per day, and a maximum dose of up to $1.8 \mathrm{mg} / \mathrm{kg}$ per day in most studies. Atomoxetine was administered either once daily (3 studies) or as a divided twice-daily dose (10 studies). Dosing during the extension phase represented a continuation of the treatment received during the acute phase. If at any time a patient or investigator felt that the patient was not obtaining sufficient clinical benefit from treatment, participation could be terminated.

In addition to the DSM-IV and K-SADS-PL diagnostic entry criteria, initial criteria required symptom severity to be at least 1.5 standard deviations (SD) above age and sex norms in 6 of the 13 studies, and at least 1.0 SD above norms in three of the studies, as assessed with the Attention-Deficit/Hyperactivity Disorder Rating Scale-IV-Parent Version: Investigator Administered and Scored (ADHDRS-IV-Parent:Inv; DuPaul et al. 1998; Faries et al. 2001). Patients of any diagnostic subtype of ADHD were eligible to participate. Exclusion criteria included serious medical illness, mental retardation, abnormal baseline laboratory values, abnormal baseline electrocardiograms, organic brain disorders, a history of psychosis or bipolar disorder, alcohol or drug abuse within the past 3 months, and ongoing use of psychoactive medication other than the study drug. Patients were recruited by referral and by advertisement. The studies were approved at each site by an Insti- 
tutional Review Board and were conducted in accordance with the ethical standards of the 1975 Declaration of Helsinki, as revised in 2000 (World Medical Association 2000). Parents and guardians signed consent forms, and assent was given by patients before enrollment.

\section{Assessments and statistical methods}

A portion of patients received only placebo treatment during the pre-extension treatment period and were therefore exposed to atomoxetine for the first time during the extension phase. Accordingly, time zero for this analysis was defined as the time at which a patient began receiving atomoxetine, whether in the pre-extension trial or in the extension phase. Weight was measured at every visit in each trial, and height was measured at the initial and final study visits of the initial trial and at regular intervals not to exceed 6 months during the extension phase.

Mean observed values and changes from baseline of weight, height, and BMI were obtained and expressed as a percentile and corresponding $z$-score relative to population normative values for age and sex using the most current norms from the National Center for Health Statistics (NCHS) (Kuczmarski et al. 2000). Significance of changes from baseline was assessed with Student's $t$-test and Wilcoxon's signed rank test. Extreme cases of difference from expected weight or height were identified from patients' baseline-to-end point change $z$-scores, with extreme cases identified by a change $z$-score below -1.96 or above +1.96 , a threshold equivalent to the limits of a two-tailed 95\% confidence interval. Longitudinal models such as the mixed-model repeated measures analysis of variance were used to assess changes over time. Dose effects were examined using a regression model for change in weight, height, or BMI $z$-score versus modal dose. Categorical data were assessed with Fisher's exact test. All tests were conducted using a two-sided significance level of 0.05.

\section{RESULTS}

\section{Patient sample}

A total of 1,312 patients entered the longterm study. As indicated in Table 1, the major-
Table 1. Patient Demographics and Baseline Characteristics

\begin{tabular}{lcc}
\hline $\begin{array}{c}\text { All patients } \\
\text { Characteristic }\end{array}$ & $\begin{array}{c}5 \text {-year patients } \\
(\mathrm{N}=1,312)\end{array}$ \\
\hline Sex, $n(\%)$ & & \\
$\quad$ Female & & \\
Male & $308(23.5)$ & $(21.3)$ \\
Racial origin, $n(\%)$ & $1,004(76.5)$ & $48(78.7)$ \\
$\quad$ African American & $95(7.2)$ & $3(4.9)$ \\
Caucasian & $1,084(82.6)$ & $53(86.9)$ \\
East Asian & $9(0.7)$ & $0(0.0)$ \\
Hispanic & $75(5.7)$ & $3(4.9)$ \\
Other & $49(3.7)$ & $2(3.3)$ \\
Age at entry, years & $11.0(2.5)$ & $10.2(1.7)$ \\
Mean (SD) & $6.1-18.0$ & $6.2-13.4$ \\
Range & & \\
ADHD Subtype, $n(\%)$ & $849(64.8)$ & $51(83.6)$ \\
Combined & $38(2.9)$ & $1(1.6)$ \\
Hyperactive/Impulsive & $370(28.2)$ & $9(14.8)$ \\
Inattentive & $881(67.8)$ & $39(63.9)$ \\
Prev. Stim. Exp., $n$ (\%) &
\end{tabular}

$\mathrm{SD}=$ Standard deviation; ADHD = attention-deficit $/$ hyperactivity disorder; Prev. Stim. Exp. = previous exposure to stimulants.

ity $(76.5 \%)$ were boys, with a mean age at first exposure to atomoxetine of 11.0 years $(\mathrm{SD}=$ 2.5). Most (82.6\%) were of Caucasian origin. The most prevalent diagnostic category among the 1,257 patients providing data was ADHD of the combined type $(64.8 \%)$, while $28.2 \%$ were predominantly inattentive and $2.9 \%$ were predominantly hyperactive-impulsive. The final mean dose of atomoxetine was $1.46 \mathrm{mg} / \mathrm{kg}$ per day $(\mathrm{SD}=0.53)$. Sixty one patients to date have reached the 5-year time point. This report will focus on their longitudinal data set, as it is the most complete. Demographics and baseline characteristics for the 5-year subsample were not appreciably different from those of the overall study sample (Table 1), although proportionally fewer patients diagnosed with the predominantly inattentive subtype of ADHD have reached the 5-year time point than have entered the study initially. To date, 384 patients $(29.3 \%)$ remain enrolled in the study, having not yet reached the 5-year time point. Another $926(70.6 \%)$ have discontinued. The most frequent reason for discontinuation to date has been Personal Conflict/Other (25.4\%), followed by Loss to Follow-up (16.5\%). Lack of Efficacy accounts for $16.3 \%$, while Adverse Event accounts for $5.3 \%$. Of the latter, only 1 
patient $(0.1 \%)$ cited weight loss and $2(0.2 \%)$ cited decreased appetite as the adverse event leading to discontinuation.

\section{Weight results}

At baseline, the observed-case mean weight for the subsample of patients who have stayed in the study and to date have reached 5 years of therapy was $40.2 \mathrm{~kg}(\mathrm{SD}=13.0)$, or $88.4 \mathrm{lb}(\mathrm{SD}=$ 28.6), corresponding to a mean weight percentile of 67.8 (Table 2), well above the NCHS median. After 1 month of treatment, a significant decrement was seen relative to the expected weight (Fig. 1A), with patients falling to the 66.2 percentile (observed-case mean change from baseline: -1.6 percentage points, $\mathrm{SD}=3.5, n=61$, $p<0.001)$. A maximum decrement from expected was reached at the 15th month of treatment, with patients falling to the 57.9 percentile (mean change: -9.9 percentage points, $\mathrm{SD}=$ $14.2, p<0.001)$. By the 36th month, the weight was no longer significantly different from expected, with patients' weight having risen to the 65.4 percentile (mean change: -3.1 percentage points, $\mathrm{SD}=19.9, p=0.12$ ), and by the 5 -year time point, patients had slightly overshot their starting weight percentile, although not significantly so, rising to the 70.5 percentile (mean change: +2.6 percentage points, $\mathrm{SD}=22.8$, $p=0.75)$. The last-observation-carried-forward mean weight difference from expected at 5 years, based on the starting percentile and extrapolating from the growth norms for age- and sex-matched controls, rather than from the percentile alone, was an increase relative to baseline of $+1.1 \mathrm{~kg}(\mathrm{SD}=12.7)$, or $2.4 \mathrm{lb}(\mathrm{SD}=27.9)$, representing a statistically nonsignificant increase from the starting percentile of 1.1 points $(\mathrm{SD}=22.4, p=0.70)$. No extreme cases of a shortfall from predicted weight were found, and one case of extreme gain was seen, with a patient starting the study with a height z-score of -0.61 , equivalent to a percentile score of 26.9, and completing with a $z$-score of +2.10 , equivalent to a percentile score of 93.1, an increase of $48.6 \mathrm{~kg}(106.9 \mathrm{lb})$ over the 5-years of the study, rather than the $27.6 \mathrm{~kg}(60.7 \mathrm{lb})$ that was expected for this patient. Examination of the overall sample revealed no effects of modal dose on changes in weight $z$-score $\left(r^{2}<0.001, p=0.85\right)$.

When patients who had reached the 5-year time point were stratified on the basis of their starting weight quartile, a pattern of differential growth in weight was observed over the 5year observation period (Table 3 ). The greatest gains were seen in the patients who were lightest at study entry. Patients with weight per-

Table 2. Changes in Weight, Height, and Body Mass Index from Baseline to the Five-Year Time Point

\begin{tabular}{|c|c|c|c|c|c|}
\hline Measure & Value & $\begin{array}{c}\text { Baseline: } \\
\text { mean (SD) }\end{array}$ & $\begin{array}{l}\text { 5-Year } \\
\text { time point: } \\
\text { mean }(S D)\end{array}$ & $\begin{array}{c}\text { Change: } \\
\text { mean (SD) }\end{array}$ & $\mathrm{p}$ value \\
\hline \multirow{6}{*}{$\begin{array}{l}\text { Weight } \\
\qquad(n=61)\end{array}$} & Actual (kg) & $40.2(13.0)$ & $70.0(20.0)$ & +29.8 (13.3) & $<0.001$ \\
\hline & Predicted (kg) & - & $68.9(17.1)$ & $+28.7(7.6)$ & $<0.001$ \\
\hline & Actual (lb) & $88.4(28.6)$ & $153.9(44.0)$ & $+66.5(29.3)$ & - \\
\hline & Predicted (lb) & - & $151.5(37.7)$ & +63.1 (16.8) & - \\
\hline & $z$-score ${ }^{a}$ & $0.72(1.07)$ & $0.77(1.09)$ & $+0.05(0.79)$ & 0.62 \\
\hline & Percentile & $67.8(28.1)$ & $68.9(27.4)$ & +1.1 (22.4) & 0.70 \\
\hline \multirow{6}{*}{$\begin{array}{l}\text { Height } \\
\qquad(n=53)\end{array}$} & Actual (cm) & 139.9 (11.7) & $170.0(9.6)$ & $+30.1(8.2)$ & $<0.001$ \\
\hline & Predicted $(\mathrm{cm})$ & - & $169.7(9.3)$ & +29.8 (6.9) & $<0.001$ \\
\hline & Actual (in) & $55.1(4.6)$ & $66.9(3.8)$ & +11.9 (3.2) & - \\
\hline & Predicted (in) & - & $66.8(3.6)$ & +11.7 (2.7) & - \\
\hline & $z$-score ${ }^{a}$ & $0.23(1.00)$ & $0.27(1.01)$ & $+0.04(0.75)$ & 0.71 \\
\hline & Percentile & $55.7(28.9)$ & $57.9(29.6)$ & $+2.1(23.6)$ & 0.52 \\
\hline \multirow{4}{*}{$\begin{array}{l}\mathrm{BMI} \\
\qquad(n=52)\end{array}$} & Actual & $19.5(3.8)$ & $24.1(5.6)$ & $+4.5(3.5)$ & $<0.001$ \\
\hline & Predicted & - & $24.0(5.0)$ & $+4.4(1.6)$ & $<0.001$ \\
\hline & $z$-score ${ }^{a}$ & $0.73(1.01)$ & $0.70(1.09)$ & $-0.03(0.83)$ & 0.82 \\
\hline & Percentile & $70.3(25.8)$ & $68.1(28.4)$ & $-2.2(24.1)$ & 0.52 \\
\hline
\end{tabular}

$\mathrm{SD}=$ Standard deviation; $\mathrm{BMI}=$ body mass index; $\mathrm{kg}=$ kilogram; $\mathrm{lb}=$ pound; $\mathrm{cm}=$ centimeter; in $=$ inch.

az-Scores are standard scores that indicate how far, and in what direction, an item deviates from its distribution's mean, expressed in units of its distribution's standard deviation. 
A

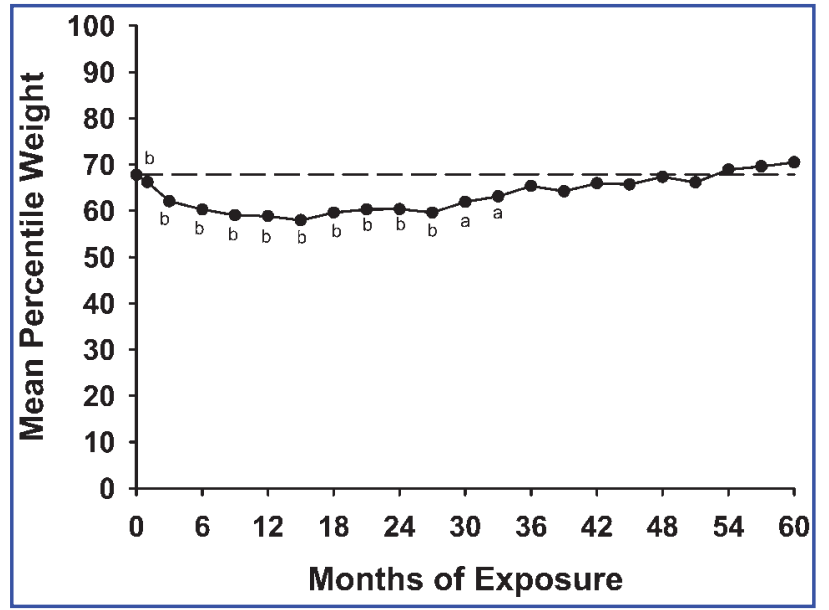

B

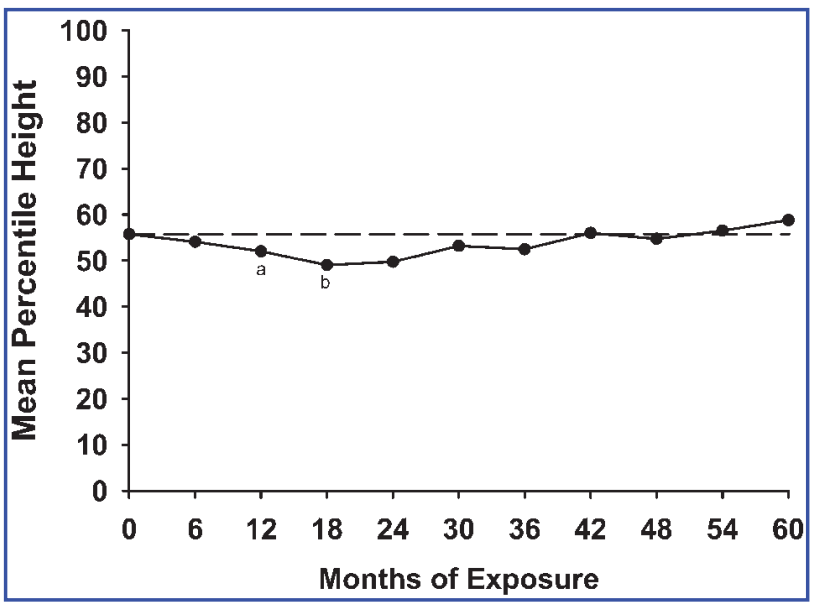

FIG. 1. Mean percentile weight (A) and height (B) as a function of time of exposure to atomoxetine. Data include all patients with a baseline measurement and a measurement at or after the 5-year time point. The dashed lines indicate the baseline percentiles. The number of patients at each data point varies between 53 and 61 for the weight curve, and between 51 and 53 for the height curve, due to the fact that not all patients provided both sets of data at each time point. ${ }^{\mathrm{a}} p<0.05$, relative to baseline percentile; ${ }^{\mathrm{b}} p<0.001$, relative to baseline percentile.

centiles that fell into successively higher quartiles at baseline showed successively smaller increases in weight percentile, with the heaviest group at baseline in fact showing a significant decrease in weight percentile at the 5-year time point.

\section{Height results}

Observed-case mean height at baseline for the patients to date who have reached the 5year time point was $139.9 \mathrm{~cm}(\mathrm{SD}=11.7)$, or 4 feet 7 inches (SD $=4.6$ inches), corresponding to a mean height percentile of 55.7 (Table 2), slightly above the NCHS median. Twelve months after initiation, a significant decrement from expected height was apparent, with patients' mean height percentiles falling to the 52.0 percentile (mean change from baseline: -3.4 percentage points, $\mathrm{SD}=10.8, n=45, p=$ $0.022)$. A maximum decrement from expected height was reached by the 18-month time point (Fig. 1B), with patients' mean height falling to the 49.0 percentile (mean change: -6.6 per-

Table 3. Changes in Weight, Height, and Body Mass Index Percentile from Baseline to the Five-Year Time Point, by Baseline Quartile

\begin{tabular}{|c|c|c|c|c|c|c|}
\hline Measure & $\begin{array}{c}\text { Baseline } \\
\text { percentile } \\
\text { range }\end{array}$ & $\mathrm{n}$ & $\begin{array}{l}\text { Baseline: } \\
\text { mean (SD) }\end{array}$ & $\begin{array}{l}\text { 5-Year } \\
\text { time point: } \\
\text { mean }(S D)\end{array}$ & $\begin{array}{c}\text { Change: } \\
\text { mean (SD) }\end{array}$ & $\begin{array}{c}\mathrm{p} \text { value } \\
\text { for group } \\
\text { differences }^{\text {a }}\end{array}$ \\
\hline \multirow[t]{4}{*}{ Weight percentile } & 0 to 25 th & 5 & $15.7(6.6)$ & $39.6(30.4)$ & $+23.8(28.5)$ & 0.14 \\
\hline & 25 th to 50 th & 17 & $41.0(7.2)$ & $51.5(24.9)$ & $+10.4(25.7)$ & 0.11 \\
\hline & 50th to 75 th & 8 & $62.7(8.4)$ & $65.9(22.3)$ & $+3.2(16.9)$ & 0.61 \\
\hline & 75th to 100 th & 31 & $92.2(7.2)$ & $84.0(19.5)$ & $-8.2(15.8)$ & 0.007 \\
\hline \multirow[t]{4}{*}{ Height percentile } & 0 to 25 th & 11 & $16.0(7.3)$ & $30.2(24.7)$ & $+14.1(20.8)$ & 0.048 \\
\hline & 25 th to 50 th & 13 & $38.0(6.0)$ & $54.3(25.7)$ & $+16.3(22.9)$ & 0.025 \\
\hline & 50th to 75 th & 8 & $59.3(8.2)$ & $43.3(15.1)$ & $-15.9(10.7)$ & 0.004 \\
\hline & 75 th to 100 th & 21 & $86.2(6.6)$ & $80.1(21.6)$ & $-6.1(21.7)$ & 0.21 \\
\hline \multirow{4}{*}{ BMI percentile } & 0 to 25 th & 3 & $9.9(12.9)$ & $47.6(44.2)$ & $+37.7(33.5)$ & 0.19 \\
\hline & 25 th to 50 th & 11 & $42.7(6.4)$ & $47.6(24.2)$ & $+5.0(22.8)$ & 0.49 \\
\hline & 50 th to 75 th & 11 & $63.3(6.0)$ & $57.9(28.6)$ & $-5.5(27.4)$ & 0.52 \\
\hline & 75 th to 100 th & 27 & $91.1(7.0)$ & $83.0(19.9)$ & $-8.2(17.9)$ & 0.026 \\
\hline
\end{tabular}

$\mathrm{SD}=$ Standard deviation; BMI = body mass index.

${ }^{a} p$ values were derived from paired $t$-tests to assess within-group differences. 
centage points, $\mathrm{SD}=13.1, p<0.001$ ), but by 24 months, mean percentile was no longer significantly different from expected, with patients' mean height rising slightly to the 49.7 percentile (mean change: -3.9 percentage points, $\mathrm{SD}=15.2, p=0.09)$. By the 54th month, patients slightly overshot their starting percentile (mean change: +0.2 percentage points, $\mathrm{SD}=$ $24.5, p=0.99)$, and at 5 years, patients were at the 58.8 percentile (mean change: +2.7 percentage points, $\mathrm{SD}=23.9, p=0.48$ ). The lastobservation-carried-forward mean height difference from expected at 5 years, extrapolating from the growth norms for age- and sexmatched controls, was $+0.3 \mathrm{~cm}(\mathrm{SD}=5.3)$, or +0.1 inches $(\mathrm{SD}=2.1$ inches), a statistically nonsignificant increase in percentile of 2.1 points $(\mathrm{SD}=23.6, p=0.517)$. One extreme case of a decrement from predicted height was found, with a patient starting the study with a height $z$-score of +1.10 , equivalent to a percentile score of 86.4 , and completing with a $z$ score of -2.37 , equivalent to a percentile score of 10.30, in effect, a growth of just $4.5 \mathrm{~cm}(1.8$ inches) over the 5-years of the study, rather than the $19.8 \mathrm{~cm}$ (7.8 inches) that was expected for this patient. No cases of extreme gain in height were seen. Examination of the overall sample revealed no effects of modal dose on changes in height $z$-score $\left(r^{2}<0.001, p=0.89\right)$.

Stratified on the basis of starting height quartiles, patients reaching the 5-year time point again showed differential growth patterns over the 5 -year observation period (Table 3 ). While not exactly a graded pattern as for weight percentiles, patients in the lower two quartiles showed significantly greater increases in height relative to age and sex norms, with the shortest patients at baseline demonstrating the largest mean increase in height percentile. Patients in the upper quartiles, by contrast, showed decreases in height percentile from baseline, with the greatest decrease, reaching statistical significance, occurring in the third quartile. These patients, on average, arrived at the 5-year time point with a height that was in fact below the median. The decrease in the highest baseline quartile was considerably less, and the difference from baseline did not achieve statistical significance.
BMI results

Observed-case mean BMI at baseline for patients reaching the 5-year time point (Table 2) was $19.5(\mathrm{SD}=3.8)$, corresponding to a mean BMI percentile of 70.3, nowhere near levels of obesity, but again well above the norm for ageand sex-matched peers. By the 5-year time point, patients' mean BMI percentile had fallen slightly to $68.1(\mathrm{SD}=28.4)$, a 2.2-point decrease from baseline $(p=0.52)$. No extreme cases of a shortfall from predicted BMI were found, and one case of extreme gain was seen, with a patient starting the study with a BMI z-score of -0.68 , equivalent to a percentile score of 24.8 , and completing with a $z$-score of +2.05 , equivalent to a percentile score of 91.5, an increase in BMI from 15.2 at baseline to 24.7 at the 5year time point. This case involved a different patient from those involved in the cases of extreme gain in weight or extreme decrement in height. Examination of the overall sample revealed no effects of modal dose on changes in BMI $z$-score $\left(r^{2}<0.001, p=0.94\right)$. Stratified by starting BMI quartile, patients again showed a graded pattern of growth over the 5-year observation period (Table 3), but the only statistically significant change in percentile occurred in the patients with highest BMIs at baseline, possibly reflecting the decrease in weight percentile among patients in the top quartile for weight at baseline.

\section{DISCUSSION}

These results represent the largest data set to date of patients studied for the effects of ADHD treatment on growth over such an extended period. The findings indicate that there is a small, temporary decrement in growth rate associated with chronic use of atomoxetine in developing children and adolescents. The decrement of growth in weight was noticeable by the first postbaseline time point after 1 month of continuous treatment, followed nearly a year later by a very brief decrement of growth in height. Mean actual height returned to expected values by the end of the second year of treatment, and mean actual weight returned by the end of the third year, indicating that any effects on de- 
velopment overall were neither persistent nor irrecoverable. The timing of the decrement in growth rates suggests that one possible mechanism is an effect of the medication on appetite. Nausea and stomach pain are frequently reported during the early stages of treatment with atomoxetine (Kratochvil et al. 2001; Spencer et al. 2002), and it is possible that this could have influenced patients' desire to eat, as has been seen in studies involving $\mathrm{MPH}$ (Kramer et al. 2000). Alternatively, the putative loss of appetite could have been due to a temporary perturbation of the central noradrenergic systems involved in hunger or satiety (Wellman 2000), similar to the dopaminergic system-mediated appetite suppression associated with the use of the stimulants (Freed and Mizel 1952; Poindexter 1960). Alternatively, this treatment could have directly affected neuroendocrine systems involved with growth mechanisms, also known to be under catecholaminergic control, although this possibility is unlikely, given that disturbances of hormonal levels have not been seen in previous studies with atomoxetine (Kratochvil et al. 2001; Spencer et al. 2002).

The reversibility of the growth deficits seen in this study is reassuring, because it indicates that atomoxetine is unlikely to have a permanent effect on growth and final stature. These findings extend those in past studies with the compound. This is particularly salient, because younger children may be the most affected by any potential growth-suppressant effects of ADHD treatment (Faraone et al. 2005a; Spencer et al. 1996; Zachor et al. 2006), although this has not been a consistent finding (Schertz et al. 1996; Sund and Zeiner 2002). Kratochvil and colleagues (Kratochvil et al. 2006) conducted a meta-analysis of 13 studies involving atomoxetine and showed that, in young children (6-7-years old), the effects of atomoxetine on growth appeared to begin to reverse but were nevertheless still quite apparent at the 2-year time point. By contrast, an analysis by Wilens et al. (Wilens et al. 2006) of adolescents with ADHD showed a complete reversal of any effect of atomoxetine on mean height and weight by 2 years of treatment.

Underscoring these results is the finding that children are more susceptible than adolescents to treatment-emergent appetite suppression and other gastrointestinal effects (Wilens et al. 2006). This supports the notion that the effects of treatment on growth are felt more acutely in younger patients. Charach and associates (Charach et al. 2006) examined the effects of psychostimulants on growth over a period of up to 5 years in a small group of preadolescent children. Their results suggest that a "small but distinct risk" of a persistent decrement in growth rate occurs with long-term use of stimulants, and that such risk increases with the dose, particularly above recommended doses (>2.0 mg/kg per day MPH-equivalents). Despite such findings, however, the persistence of growth deficits beyond the second or third year of treatment with psychostimulants appears unlikely, as the predominance of evidence indicates that growth deficits tend to attenuate by the end of the first or second year, with growth rates returning toward expected levels by the second or third year (Satterfield et al. 1979; Poulton and Cowell 2003; Faraone et al. 2005a; Spencer et al. 2006; Zachor et al. 2006).

When patients in the present study were classified according the quartile of their starting weight, height, or BMI percentiles (relative to norms), differences in patterns of growth were seen, whereby the children who were smallest at baseline showed the greatest increases in growth above expected, while those who were largest at baseline showed the greatest decreases relative to expected. This pattern was not uniform, however, for while patients below the median for weight at baseline showed considerable increases above their predicted weight percentile at the 5-year time point, the differences from predicted in fact did not achieve statistical significance. Moreover, whereas patients below the median for height at baseline showed significant increases in height percentile over prediction, and those in the third quartile (50 to 75 percentiles) persistently showed a significantly lower height percentile from predicted, those in the top quartile showed a height percentile at 5 years that was not significantly different from predicted.

It is unclear whether these differential patterns of changes in growth reflect a true size- 
based difference of treatment on growth rates, whether children were simply "normalizing" in body size over time independently of treatment, or if this merely represents a form of statistical "regression to the mean." A "normalizing" effect is an unlikely cause, because a decrement was seen in the growth in height, as well as in weight, while a simple regression to the mean is also questionable, because the patterns of overshoot and undershoot from expected growth across size classes were not uniform, as, for example, the height decrement in the third quartile (50th to 75 th percentile) was greater than the nonsignificant decrement in the top quartile. Alternatively, patients who were smaller at baseline may represent children with a later onset of puberty, and their greater growth during treatment may simply reflect a "catching up" in size with their peers. Unfortunately, Tanner-stage data were not captured during these studies, so the current results do not address whether the patient sample showed a change in the tempo of puberty relative to norms or whether the treatment had an effect on maturation. The latter appears unlikely, however, as a previous atomoxetine study (Michelson et al. 2004) that included an assessment of Tanner stages has shown that the treatment appears not to affect maturation or its timing.

This putative differential size-based effect of treatment on growth is consistent with the results from past studies of treatments for ADHD. Studies involving the psychostimulants (Schertz et al. 1996; Faraone et al. 2005a; Zachor et al. 2006) have also revealed that children who are largest at baseline show the greatest growth deficits, whereas those who are smallest show the least effect. A common finding, and one that contradicts the stereotype of the underweight, hyperkinetic child with ADHD, is that children with ADHD in clinical trials tend to be heavier than expected from norms at baseline (Sund and Zeiner 2002; Holtkamp et al. 2004; Faraone et al. 2005b; Spencer et al. 2006). In fact, one theory suggests that there is a linkage between ADHD and obesity through what has been referred to as an "environmental oversampling disorder" (Bazar et al. 2006), a phenomenon by which an individual is predisposed to taking in an excess of environmentally supplied stimuli, with ingestive behavior merely representing one type of stimulus-seeking behavior. Other analyses suggest that the prevalence of obesity among children with ADHD may merely reflect that of the general population (Curtin et al. 2005). During long-term treatment for ADHD, weight among the heavier children appears to "normalize," and a decrease is seen over time in the proportion of overweight children. Nevertheless, deficits in weight, height, and BMI did occur among patients in the "lower quartiles as well, so considerable vigilance is still warranted in monitoring patients' tolerance to treatment with respect to growth deficits.

One point of interest in any study of changes in growth pattern during pharmacological treatment is whether any such effects are associated with the magnitude of the dose. In the present study, we found no relation between patients' modal doses of atomoxetine and the magnitude of the differences between their expected and actual growth. Similar findings have also been obtained in most studies involving the psychostimulants, because effects on growth are typically seen over the entire range of doses administered (Lisska and Rivkees 2003; Schertz et al. 1996; Pliszka et al. 2006). This contrasts with the findings by Charach et al. (Charach et al. 2006), who found that only doses of psychostimulant above the equivalent of $1.5 \mathrm{mg} / \mathrm{kg}$ per day of MPH were associated with a significant risk of a diminished growth rate for weight, whereas doses above the equivalent of $2.5 \mathrm{mg} / \mathrm{kg}$ per day were associated with a significant risk of a decreased growth rate for height. It should be noted, however, that the latter dose is at the upper end of the recommended maximum dose for stimulants $(2.0-2.5 \mathrm{mg} / \mathrm{kg}$ per day), whereas the doses of atomoxetine used in the present study were generally within the recommended range.

Because this was a long-term study, one of its limitations was the difficulty of maintaining patients in the study long enough to reach the 5year time point. Rates of discontinuation due to an adverse event $(5.3 \%)$ or lack of efficacy $(16.3 \%)$ were notably low, but the overall discontinuation rate $(70.6 \%)$ was high, as expected from a study of this length. Consequently, the 
sample size at the 5-year time point is less than optimal, making it more difficult to conduct secondary analyses of subgroups with sufficient statistical power. Moreover, the data taken at the 5-year time point represent a somewhat skewed sample, because patients who were able to remain in the study for that length of time may not be representative of those who were not. This may be a minor point, however, as the overwhelming majority of discontinuations occurred for reasons not related to tolerance or efficacy. Also ameliorating this weakness to some extent is the fact that this was a large study, with an entering sample size of well over a thousand patients. Doses were well controlled and kept within recommended guidelines, so that, while the study sample may not represent a naturalistic and numerically defined cohort as in the only other 5-year drug growth study to date, conducted by Charach et al. (Charach et al. 2006), the present study avoids many of the limitations of that study, which was characterized by incomplete descriptions of patient disposition and heterogeneous levels of exposure within its defined dose ranges. Nevertheless, another source of skewing arises from the nature of the North American ADHD patient population itself, which the sample reflects in consisting of a majority of males, Caucasians, and patients of the combined diagnostic subtype. Therefore, these findings may not generalize to each ADHD patient, although the findings with this sample should be still representative of the overall U.S. patient population.

Due also to its long-term nature, this study was conducted under nonrandomized, openlabel conditions, because it would have been unethical to maintain a patient on placebo for such a protracted period. This makes it difficult to discern whether observed changes or differences from norms are due to the treatment or to the condition itself. The previous discussion of obesity illustrates the confusion that can be generated from the reliance on standard growth curves in the absence of a control for the untreated disease state. The situation is further complicated by the recalibration that such standard curves have undergone, such that the median weight they now describe is more prescriptive than descriptive in nature. Although the average weight in the population has been increasing over time, average height has remained stable. To avoid contributing to the trend of increasing obesity in the United States, the standards committee that constructed the most recent norms decided to use the population statistic for weight from earlier studies with lower mean absolute values. As a result, the average relative weight in the population today is expected to be greater than the 50th percentile described by the growth curves currently used as the norm.

In summary, these findings show that use of atomoxetine among 6- to 18-year-olds is associated with a modest slowing of growth velocity over the initial 18 months, followed by a return to expected weights and heights by $2-3$ years. Mean $z$-scores and percentiles for weight, height, and BMI were not significantly different from baseline from approximately the 3-year time point onward. However, analysis by quartile showed that weight deficits persisted to the 5-year time point among patients who were heaviest at baseline, and patients in the top quartile at baseline showed a significant mean decrease in BMI. In contrast, patients who were shortest at baseline showed a significant mean increase in height above expected. These results suggest that, for most children and adolescents with ADHD, atomoxetine appears unlikely to have a persistent effect on growth and final stature, although some younger patients who are heavier or taller than average may show persistent decreases from expected weight or height over time.

\section{DISCLOSURES}

This work was sponsored by Eli Lilly and Company. Dr. Spencer receives research support from Shire, Lilly, GlaxoSmithKline, Pfizer, McNeil, Novartis, and the National Institute of Mental Health (NIMH), is a member of speaker's bureaus for GlaxoSmithKline, Lilly, Novartis, Wyeth, Shire, and McNeil, and serves on advisory boards for Shire, Lilly, GlaxoSmithKline, Pfizer, McNeil, and Novartis. Dr. Kratochvil is supported by NIMH Grant 5K23MH06612701A1, receives study drug for an NIMH-funded study from Lilly, receives grant support from Lilly, McNeil, Abbott, 
and Cephalon, is a consultant for Lilly, Shire, Cephalon, Organon, AstraZeneca, BoehringerIngelheim, Abbott, and Pfizer, and is a member of the Lilly speaker's bureau. Dr. Sangal has received research support within the past 5 years from Lilly, GlaxoSmithKline, Cephalon, SanofiAventis, Somaxon, Merck, Organon, Novartis, Takeda, and Pfizer. Dr. Saylor receives research/consultancy support from Lilly, BristolMyers Squibb, Shire, McNeil, New River, and Otsuka. Dr. Bailey is a consultant, an advisory board member, and on the speaker bureau for Lilly, and has participated in research as an investigator with Lilly, McNeil, Novartis, Shire, Bristol-Meyers Squibb, UCB, Cephalon, and Sanofi-Aventis. Dr. Dunn receives grant support from Lilly, McNeil, Otsuka, and Psychogenics and is a speaker for Lilly and McNeil. Dr. Geller receives/d research support from, is/has been a speaker for, or is/has been on the advisory board for the following: Shire, Lilly, Pfizer, Bristol-Myers Squibb, Novartis, Forest, and GlaxoSmithKline, and other sources of research support include: private foundations: Obsessive Compulsive Foundation, Tourette Syndrome Association, Wallace Foundation, McIngvale Family Foundation, NIH: NIMH, NINDS. Dr. Casat receives research grant support from AstraZeneca, Bristol-Myers Squibb, Lilly, GlaxoSmithKline, Novartis, Sanofi-Aventis, and Shire, and serves on the speaker panel for UCB and an advisory board for Lilly. Dr. Lipetz has received research support from Lilly and has served on their speaker panel and advisory board. He has no other financial relationships with industry. Dr. Jain receives research grants from Lilly, Forest, GlaxoSmithKline, Merck, Pfizer, and Sepracore, serves as a consultant for Lilly and as a speaker for GlaxoSmithKline, Pfizer, Wyeth, and Lilly. Dr. Newcorn receives grant support from Lilly, Novartis, Ortho-McNeil, and Shire, is a consultant to Lilly, Novartis, Ortho-McNeil, and Shire, is a speaker for Lilly, Novartis, Ortho-McNeil, Shire, and Cephalon, and is a member of advisory boards at Lilly, Novartis, Ortho-McNeil, Shire, and Cephalon. Drs. Ruff, Feldman, and Allen are employees and shareholders of Lilly and Company. Ms. Furr was supported as a summer intern by Lilly and has no other financial relationships.

\section{ACKNOWLEDGMENT}

The authors are grateful to Mr Kurt Baker for his contributions to the statistical programming of these analyses.

\section{REFERENCES}

American Psychiatric Association. Diagnostic and Statistical Manual of Mental Disorders, 4th ed. (DSM-IV). Washington (DC), American Psychiatric Association, 1994.

American Psychiatric Association: Diagnostic and Statistical Manual of Mental Disorders, 4th Edition, Text Revision (DSM-IV-TR). Washington (DC), American Psychiatric Association, 2000.

Andres Carrasco MA, Catala MA, Gomez-Beneyto M: Study of the prevalence of the attention deficit hyperactivity disorder in ten-year-old children living in the Valencia metropolitan area. Actas Luso Esp Neurol Psiquiatr Cienc Afines 23:184-188, 1995.

Bazar KA, Yun AJ, Lee PY, Daniel SM, Doux JD: Obesity and ADHD may represent different manifestations of a common environmental oversampling syndrome: A model for revealing mechanistic overlap among cognitive, metabolic, and inflammatory disorders. Med Hypotheses 66:263-269, 2006.

Charach A, Figueroa M, Chen S, Ickowicz A, Schachar R: Stimulant treatment over 5 years: Effects on growth. J Am Acad Child Adolesc Psychiatry 45:415-421, 2006.

Curtin C, Bandini LG, Perrin EC, Tybor DJ, Must A: Prevalence of overweight in children and adolescents with attention deficit hyperactivity disorder and autism spectrum disorders: A chart review. BMC Pediatrics 5:48, 2005.

DuPaul GJ, Power TJ, Anastopoulos AD, Reid R: ADHD Rating Scale-IV: Checklists, Norms, and Clinical Interpretations. New York, The Guilford Press, 1998.

Faraone SV, Biederman J, Monuteaux M, Spencer T: Longterm effects of extended-release mixed amphetamine salts treatment for attention-deficit/hyperactivity disorder on growth. J Child Adolesc Psychopharmacol 15:191-202, 2005a.

Faraone SV, Biederman J, Spencer TJ, Michelson D, Adler LA, Reimherr FW, Glatt SJ: Efficacy of atomoxetine in adult attention-deficit/hyperactivity disorder: A drug-placebo response curve analysis. Behav Brain Funct 1:16, $2005 \mathrm{~b}$.

Faries DE, Yalcin I, Harder D, Heiligenstein JH: Validation of the ADHD Rating Scale as a clinician administered and scored instrument. J Atten Disord 5:39-47, 2001.

Freed SC, Mizel M: The use of amphetamine combinations for appetite suppression. Ann Int Med 36:14921497, 1952.

Holtkamp K, Konrad K, Müller B, Heussen N, Herpertz S, Herpertz-Dahlmann B, Hebebrand J: Overweight and obesity in children with attention-deficit/hyperactivity disorder. Int J Obes 28:685-689, 2004.

Kaufman J, Birmaher B, Brent D, Rao U, Ryan N: KiddieSADS-Present and Lifetime Version (K-SADS-PL). Pittsburgh, University of Pittsburgh Press, 1996. 
Kramer JR, Loney J, Ponto LB, Roberts MA, Grossman S: Predictors of adult height and weight in boys treated with methylphenidate for childhood behavior problems. J Am Acad Child Adolesc Psychiatry 39:517-524, 2000.

Kratochvil CJ, Wernicke JF, Michelson D, Vaughan B, Bohac D, Harrington M, Baker N, May D, Burke WJ: Long-term safety of atomoxetine in the treatment of ADHD. Presented at The 48th Annual Meeting of the American Academy of Child and Adolescent Psychiatry, October 23-28, 2001, Honolulu, HI, Abstract number P119.

Kratochvil CJ, Wilens TE, Greenhill LL, Gao H, Baker KD, Feldman PD, Gelowitz DL: Effects of long-term atomoxetine treatment for young children with attentiondeficit/hyperactivity disorder. J Am Acad Child Adolesc Psychiatry 45:919-927, 2006.

Kuczmarski RJ, Ogden CL, Grummer-Strawn LM, Flegal KM, Guo SS, Wei R, Mei Z, Curtin LR, Roche AF, Johnson CL: CDC growth charts: United States. Advance data from vital and health statistics. Report Nr. 314. Hyattsville (Maryland), National Center for Health Statistics, 2000.

Lisska MC, Rivkees SA: Daily methylphenidate use slows the growth of children: A community based study. J Pediatr Endocrinol Metab 16:711-718, 2003.

Michelson D, Faries D, Wernicke J, Kelsey D, Kendrick K, Sallee FR, Spencer T, Atomoxetine ADHD Study Group: Atomoxetine in the treatment of children and adolescents with attention-deficit/hyperactivity disorder: A randomized, placebo-controlled, dose-response study. Pediatrics 108:e83, 2001.

Michelson D, Spencer T, Bangs M, Zhang S, Ruff D, Gao $H$, Feldman P: Developmental outcomes of long-term atomoxetine treatment in ADHD. Presented at The 51st Annual Meeting of the American Academy of Child and Adolescent Psychiatry, October 19-24, 2004; Washington, DC. Abstract number A2.

MTA Cooperative Group: National Institute of Mental Health Multimodal Treatment Study of ADHD followup: Changes in effectiveness and growth after the end of treatment. Pediatrics 113:762-769, 2004.

Pliszka SR, Matthews TL, Braslow KJ, Watson MA: Comparative effects of methylphenidate and mixed salts amphetamine on height and weight in children with attention-deficit/hyperactivity disorder. J Am Acad Child Adolesc Psychiatry 45:520-526, 2006.

Poindexter A: Appetite suppressant drugs: A controlled clinical comparison of benzphetamine, phenmetrazine, d-amphetamine and placebo. Curr Ther Res Clin Exp 2:354-363, 1960.

Poulton A, Cowell CT: Slowing of growth in height and weight on stimulants: A characteristic pattern. J Paediatr Child Health 39:180-185, 2003.

Safer D, Allen R, Barr E: Depression of growth in hyperactive children on stimulant drugs. N Engl J Med 287:217-220, 1972.

Satterfield JH, Cantwell DP, Schell A, Blaschke T: Growth of hyperactive children treated with methylphenidate. Arch Gen Psychiatry 36:212-217, 1979.
Schertz M, Adesman AR, Alfieri NE, Bienkowski RS: Predictors of weight loss in children with attention deficit hyperactivity disorder treated with stimulant medication. Pediatrics 98:763-769, 1996.

Spencer TJ, Biederman J, Harding M, O'Donnell D, Faraone SV, Wilens TE: Growth deficits in ADHD children revisited: Evidence for disorder-associated growth delays? J Am Acad Child Adolesc Psychiatry 35:1460-1469, 1996.

Spencer TJ, Heiligenstein JH, Biederman J, Faries DE, Kratochvil CJ, Conners CK, Potter WZ: Results from 2 proof-of-concept, placebo-controlled studies of atomoxetine in children with attention-deficit/hyperactivity disorder. J Clin Psychiatry 63:1140-1147, 2002.

Spencer TJ, Newcorn JH, Kratochvil CJ, Ruff D, Michelson D, Biederman J: Effects of atomoxetine on growth after 2-year treatment among pediatric patients with attention-deficit/hyperactivity disorder. Pediatrics 116:e74-e80, 2005.

Spencer TJ, Faraone SV, Biederman J, Lerner M, Cooper KM, Zimmerman B, Concerta Study Group: Does prolonged therapy with a long-acting stimulant suppress growth in children with ADHD? J Am Acad Child Adolesc Psychiatry 45:527-537, 2006.

Sund AM, Zeiner P: Does extended medication with amphetamine or methylphenidate reduce growth in hyperactive children? Nord J Psychiatry 56:53-57, 2002.

Wang YC, Chong MY, Chou WJ, Yang JL: Prevalence of attention deficit hyperactivity disorder in primary school children in Taiwan. J Formos Med Assoc 92:133-138, 1993.

Wellman PJ: Norepinephrine and the control of food intake. Nutrition 16:837-842, 2000.

Wilens TE, Kratochvil C, Newcorn JH, Gao H: Do children and adolescents with ADHD respond differently to atomoxetine? J Am Acad Child Adolesc Psychiatry 45:149-157, 2006.

World Medical Association: Declaration of Helsinki: Recommendations Guiding Medical Doctors in Biomedical Research Involving Human Subjects. As adopted by the 18th World Medical Association General Assembly, Helsinki, Finland, June 1964 and amended by the 52nd General Assembly, Edinburgh, Scotland, October 2000.

Zachor DA, Roberts AW, Hodgens JB, Isaacs JS, Merrick J: Effects of long-term psychostimulant medication on growth of children with ADHD. Res Dev Disabil 27:162-174, 2006.

Address reprint requests to: Dr. Thomas J. Spencer Pediatric Psychopharmacology Clinic Massachusetts General Hospital / Harvard Medical School 55 Fruit Street Boston, MA 02114-2696

E-mail: spencer@helix.mgh.harvard.edu. 


\section{This article has been cited by:}

1. Joel T. Nigg. 2013. Attention-deficit/hyperactivity disorder and adverse health outcomes. Clinical Psychology Review 33:2, 215-228. [CrossRef]

2. Renata Rizzo, Mariangela GulisanoClinical Pharmacology of Comorbid Attention Deficit Hyperactivity Disorder in Tourette Syndrome 112, 415-444. [CrossRef]

3. Simona Ruggiero, Concetta Rafaniello, Carmela Bravaccio, Giampina Grimaldi, Rosario Granato, Antonio Pascotto, Liberata Sportiello, Elisabetta Parretta, Barbara Rinaldi, Pietro Panei, Francesco Rossi, Annalisa Capuano. 2012. Safety of AttentionDeficit/Hyperactivity Disorder Medications in Children: An Intensive Pharmacosurveillance Monitoring Study. Journal of Child and Adolescent Psychopharmacology 22:6, 415-422. [Abstract] [Full Text HTML] [Full Text PDF] [Full Text PDF with Links]

4. Earle E Bain, Weining Robieson, Yili Pritchett, Tushar Garimella, Walid Abi-Saab, George Apostol, James J McGough, Mario D Saltarelli. 2012. A Randomized, Double-Blind, Placebo-Controlled Phase 2 Study of $a 4 \beta 2$ Agonist ABT-894 in Adults with ADHD. Neuropsychopharmacology . [CrossRef]

5. Brigette Vaughan, Christopher J. Kratochvil. 2012. Pharmacotherapy of Pediatric Attention-Deficit/Hyperactivity Disorder. Child and Adolescent Psychiatric Clinics of North America 21:4, 941-955. [CrossRef]

6. Georgina Garcia, Grace E. Logan, Joseph Gonzalez-Heydrich. 2012. Management of Psychotropic Medication Side Effects in Children and Adolescents. Child and Adolescent Psychiatric Clinics of North America 21:4, 713-738. [CrossRef]

7. Mats Fredriksen, Anne Halmøy, Stephen V. Faraone, Jan Haavik. 2012. Long-term efficacy and safety of treatment with stimulants and atomoxetine in adult ADHD: A review of controlled and naturalistic studies. European Neuropsychopharmacology . [CrossRef]

8. Ann C. Childress, Sally A. Berry. 2012. Pharmacotherapy of Attention-Deficit Hyperactivity Disorder in Adolescents. Drugs 72:3, 309-325. [CrossRef]

9. P A Graziano, D M Bagner, J G Waxmonsky, A Reid, J P McNamara, G R Geffken. 2012. Co-occurring weight problems among children with attention deficit/hyperactivity disorder: the role of executive functioning. International Journal of Obesity 36:4, 567. [CrossRef]

10. Gigi H.H. van de Loo-Neus, Nanda Rommelse, Jan K. Buitelaar. 2011. ¿'Suspender o no el tratamiento? ¿Durante cuánto tiempo debe mantenerse el tratamiento farmacológico del trastorno por déficit de atención/hiperactividad?. Psiquiatría Biológica . [CrossRef]

11. Paula T. Trzepacz, Thomas J. Spencer, Shuyu Zhang, Mark E. Bangs, Michael M. Witte, Durisala Desaiah. 2011. Effect of atomoxetine on Tanner stage sexual development in children and adolescents with attention deficit/hyperactivity disorder: 18month results from a double-blind, placebo-controlled trial. Current Medical Research and Opinion 27:S2, 45-52. [CrossRef]

12. Gigi H.H. van de Loo-Neus, Nanda Rommelse, Jan K. Buitelaar. 2011. To stop or not to stop? How long should medication treatment of attention-deficit hyperactivity disorder be extended?. European Neuropsychopharmacology 21:8, 584-599. [CrossRef]

13. Yu-Shu Huang, Ming-Horng Tsai. 2011. Long-Term Outcomes with Medications for Attention-Deficit Hyperactivity Disorder. CNS Drugs 25:7, 539-554. [CrossRef]

14. Brigette S. Vaughan, John S. March, Christopher J. Kratochvil. 2011. The evidence-based pharmacological treatment of paediatric ADHD. The International Journal of Neuropsychopharmacology 1-13. [CrossRef]

15. J. Graham, T. Banaschewski, J. Buitelaar, D. Coghill, M. Danckaerts, R. W. Dittmann, M. Döpfner, R. Hamilton, C. Hollis, M. Holtmann, M. Hulpke-Wette, M. Lecendreux, E. Rosenthal, A. Rothenberger, P. Santosh, J. Sergeant, E. Simonoff, E. SonugaBarke, I. C. K. Wong, A. Zuddas, H.-C. Steinhausen, E. Taylor. 2011. European guidelines on managing adverse effects of medication for ADHD. European Child \& Adolescent Psychiatry 20:1, 17-37. [CrossRef]

16. Diane E. May, Christopher J. Kratochvil. 2010. Attention-Deficit Hyperactivity Disorder. Drugs 70:1, 15-40. [CrossRef]

17. Karly P. Garnock-Jones, Gillian M. Keating. 2010. Spotlight on Atomoxetine in Attention-Deficit Hyperactivity Disorder in Children and Adolescents $\dagger$. CNS Drugs 24:1, 85-88. [CrossRef]

18. Reginald P. SequeiraCentral nervous system stimulants and drugs that suppress appetite 32, 1-28. [CrossRef]

19. W Z Potter. 2009. Benefits Exceed Risks of Newer Antidepressant Medications in Youth-Maybe Not. Clinical Pharmacology \&\#38; Therapeutics 86:4, 357-359. [CrossRef]

20. Karly P. Garnock-Jones, Gillian M. Keating. 2009. Atomoxetine. Pediatric Drugs 11:3, 203-226. [CrossRef]

21. Lenard A. Adler, Thomas Spencer, Thomas E. Brown, James Holdnack, Keith Saylor, Kory Schuh, Paula T. Trzepacz, David W. Williams, Douglas Kelsey. 2009. Once-Daily Atomoxetine for Adult Attention-Deficit/Hyperactivity Disorder. Journal of Clinical Psychopharmacology 29:1, 44-50. [CrossRef] 
22. Craig Donnelly, Mark Bangs, Paula Trzepacz, Ling Jin, Shuyu Zhang, Michael M. Witte, Susan G. Ball, Thomas J. Spencer. 2009. Safety and Tolerability of Atomoxetine Over 3 to 4 Years in Children and Adolescents With ADHD. Journal of the American Academy of Child \& Adolescent Psychiatry 48:2, 176-185. [CrossRef]

23. Kenneth Towbin. 2008. Paying Attention to Stimulants: Height, Weight, and Cardiovascular Monitoring in Clinical Practice. Journal of the American Academy of Child \& Adolescent Psychiatry 47:9, 977-980. [CrossRef]

24. 2008. Current awareness: Pharmacoepidemiology and drug safety. Pharmacoepidemiology and Drug Safety 17:7, i-xvi. [CrossRef] 